\title{
Fidelity of Complex Spike-Mediated Synaptic Transmission between Inhibitory Interneurons
}

\author{
Michael T. Roberts, Kevin J. Bender, and Laurence 0. Trussell \\ Vollum Institute and Oregon Hearing Research Center, Oregon Health \& Science University, Portland, Oregon 97239
}

Complex spikes are high-frequency bursts of $\mathrm{Na}^{+}$spikes, often riding on a slower $\mathrm{Ca}^{2+}$-dependent waveform. Although complex spikes may propagate into axons, given their unusual shape it is not clear how reliably these bursts reach nerve terminals, whether their spikes are efficiently transmitted as a cluster of postsynaptic responses, or what function is served by such a concentrated postsynaptic signal. We examined these questions by recording from synaptically coupled pairs of cartwheel cells, neurons which fire complex spikes and form an inhibitory network in the dorsal cochlear nucleus. Complex spikes in the presynaptic soma were reliably propagated to nerve terminals and elicited powerful, temporally precise postsynaptic responses. Single presynaptic neurons could prevent their postsynaptic partner from firing complex but not simple spikes, dramatically reducing dendritic $\mathrm{Ca}^{2+}$ signals in the postsynaptic neuron. We suggest that rapid transmission of complex spikes may control the susceptibility of neighboring neurons to $\mathrm{Ca}^{2+}$-dependent plasticity.

Key words: complex spike; synaptic transmission; interneuron; cochlear nucleus; electrophysiology; calcium imaging

\section{Introduction}

The reliability of information transfer between neurons depends in large part on the capacity of action potentials to propagate down the axon, invade boutons, and induce neurotransmitter release. This has generally been considered a high-fidelity process, and studies in hippocampus, cortex, and cerebellum support that idea (Mackenzie and Murphy, 1998; Williams and Stuart, 1999; Cox et al., 2000; Forti et al., 2000; Koester and Sakmann, 2000; Raastad and Shepherd, 2003; Brenowitz and Regehr, 2007). Other studies, however, indicate that somatic action potentials can fail to initiate synaptic transmission under conditions that alter voltage-gated ion channel availability, such as high-frequency firing or changes in somatic membrane potential (Debanne et al., 1997; Debanne, 2004; Meeks et al., 2005).

Complex spikes are brief, high-frequency bursts of $\mathrm{Na}^{+}$action potentials, often driven by a slow, $\mathrm{Ca}^{2+}$ or synaptically mediated depolarization (Schmolesky et al., 2002; Kim and Trussell, 2007), and are produced throughout the brain (Deschênes et al., 1982; Chagnac-Amitai et al., 1990; Niespodziany and Poulain, 1995; Harris et al., 2001; Jung et al., 2001; Athanassiadis et al., 2005). The high firing frequencies and underlying waveform of complex spikes suggest that the action potentials comprising a complex spike, termed spikelets, might fail to initiate synaptic transmission. Consistent with this, recent studies in cerebellar Purkinje cells have shown that $30-60 \%$ of complex spike spikelets fail to propagate down the axon (Khaliq and Raman, 2005;

Received May 16, 2008; revised July 15, 2008; accepted Aug. 12, 2008.

This work was supported by National Institutes of Health (NIH) Grants DC004450 and NS028901, NIH Training Grants NS007381 (M.T.R., K.J.B.), DC005945 (M.T.R.), and DK007680 (K.J.B.), and a Tartar Trust fellowship (K.J.B.). We thank Sascha du Lac for providing GIN mice.

Correspondence should be addressed to Laurence 0 . Trussell, Oregon Health \& Science University, 3181 Southwest Sam Jackson Park Road, L335A, Portland, OR 97239. E-mail: trussell@ohsu.edu.

DOI:10.1523/JNEUROSCI.2226-08.2008

Copyright $\odot 2008$ Society for Neuroscience $\quad$ 0270-6474/08/289440-11\$15.00/0
Monsivais et al., 2005). It is not known, however, whether additional failures occur at the synapse or what effect failures have on postsynaptic excitability.

The dorsal cochlear nucleus (DCN) is a cerebellum-like brainstem auditory nucleus that functions in sound localization (Oertel and Young, 2004). Cartwheel cells are DCN interneurons that receive parallel fiber input and share genetic, developmental, and physiological properties with cerebellar Purkinje cells (Mugnaini et al., 1987; Berrebi et al., 1990; Ivanova and Yuasa, 1998). Like Purkinje cells, cartwheel cells fire complex spikes (Zhang and Oertel, 1993; Manis et al., 1994). Moreover, parallel fiber inputs to cartwheel cells undergo long-term plasticity that is highly dependent on the timing of presynaptic and postsynaptic activity (Tzounopoulos et al., 2004, 2007). Unlike Purkinje cells, cartwheel cells project locally, inhibiting neighboring neurons including other cartwheel cells (Berrebi and Mugnaini, 1991; Golding and Oertel, 1996, 1997; Rubio and Juiz, 2004). By recording from synaptically coupled pairs of nearby cartwheel cells, we showed previously that complex spike spikelets sometimes fail to elicit IPSCs (Tzounopoulos et al., 2004). Here, we use this approach to investigate the fidelity of unitary connections formed by complex spiking neurons. We identified properties of complex spikes that promote transmission failures and found that these failures can occur presynaptically. Surprisingly, the postsynaptic charge flux evoked by complex spikes was rather insensitive to transmission failures, suggesting that complex spikes provide a distinct signal to postsynaptic neurons. Furthermore, we showed that complex spikes inhibit postsynaptic firing over a broad time window and that this significantly alters postsynaptic calcium signaling.

\section{Materials and Methods}

Transgenic mice. A colony of transgenic mice expressing green fluorescent protein (GFP) in interneurons (GIN mice) (Oliva et al., 2000) back- 

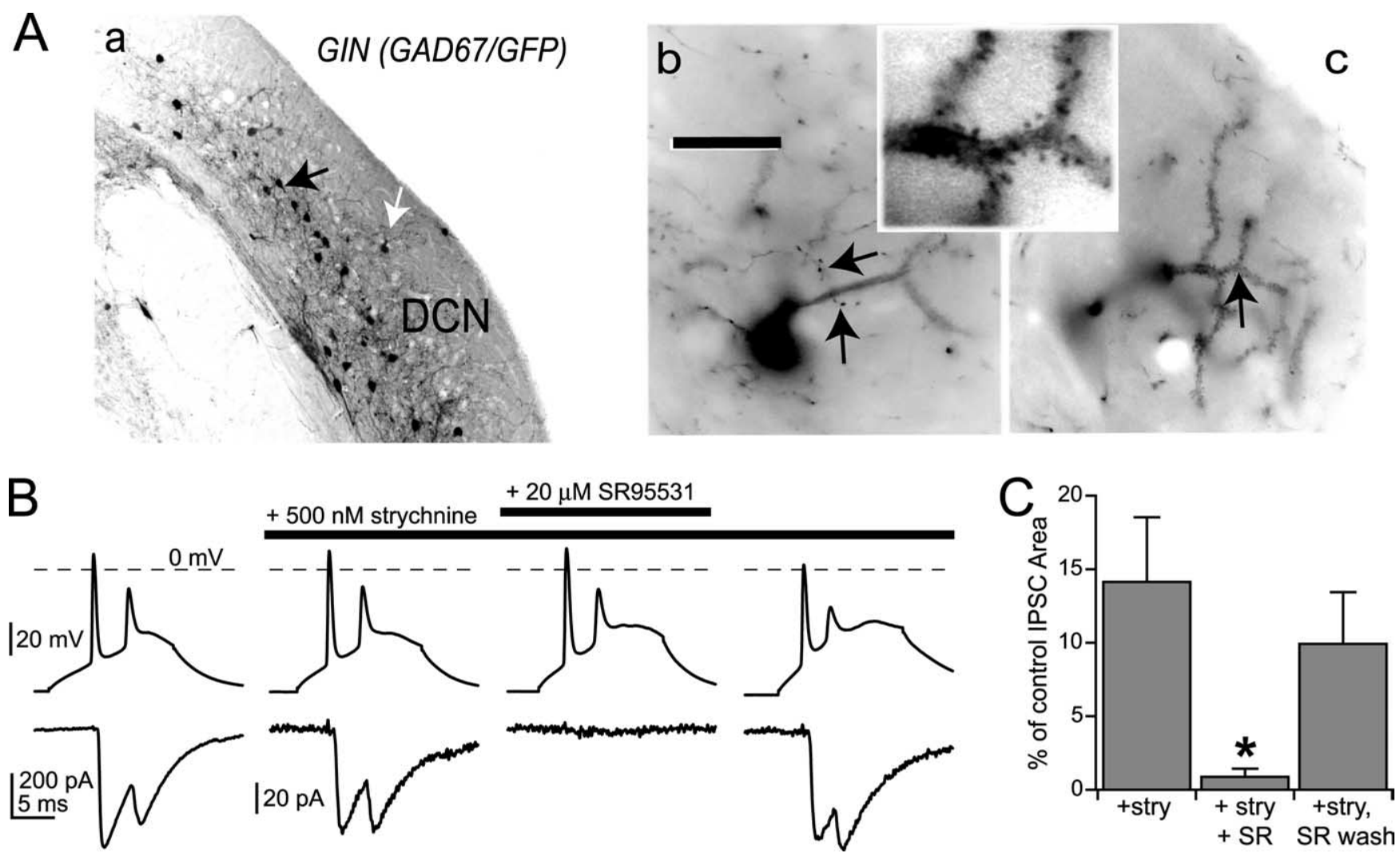

Figure 1. Synaptic transmission between cartwheel cells is predominately glycinergic. $\mathbf{A a}-\mathbf{A c}$, DCN labeling in the GIN mouse. Aa, Darkest labeling is of cells just below main cell body area (black arrow). Somewhat fainter labeling is evident in cartwheel cell (white arrow), as confirmed at higher power ( $\boldsymbol{A} \boldsymbol{b}, \boldsymbol{A c}$ ), which reveals spiny dendrites (inset) extending toward ependymal surface. Scale bar, $20 \mu \mathrm{m}$. In $\boldsymbol{A} \boldsymbol{b}$, arrows point to axonal boutons. In $\boldsymbol{A}$, arrow points at cartwheel cell dendrites. The images are negative ( $30 \mu \mathrm{m}$ fixed section). $\boldsymbol{B}$, Presynaptic complex spike comprised of two spikelets (top, left) elicited two IPSCs in a voltage-clamped postsynaptic cartwheel cell (bottom, left) $\left(V_{\text {hold }}=-83 \mathrm{mV}\right)$. Bath application of the glycine receptor antagonist strychnine ( $\left.500 \mathrm{~nm}\right)$ inhibited the majority of the IPSC. Block of GABA $A_{A}$ receptors with $20 \mu \mathrm{M}$ SR95531 reversibly abolished the remaining current. Presynaptic complex spikes are representative single trials. IPSCs are averages of 30 trials during each treatment. Data in $\boldsymbol{A}$ and $\boldsymbol{B}$ are from different preparations. $\boldsymbol{C}$, Summary of results from four pairs of cells. During the baseline phase and after full wash-in of each drug, averages of 30 trials were taken and areas under the averaged IPSCs calculated. All treatments yielded a significant reduction in IPSC area from baseline ( $p<0.05$, ANOVA). SR95531 (SR) significantly reduced the current remaining after strychnine (stry) wash-in ( ${ }^{*} p<0.05$ ). Graphics and data in $\boldsymbol{A}$ and $\boldsymbol{B}$ are from different preparations.

crossed against a C57BL/6J (Jackson Laboratories) background was established and maintained. Breeding pairs consisted of one hemizygous and one wild type. Hemizygous offspring had high expression of GFP in their spinal cords, and neonates [postnatal day 0 (P0)-P2] were reliably phenotyped by checking for fluorescence under blue light. All procedures were conducted in accordance with guidelines set by the Oregon Health and Science University Institutional Animal Care and Use Committee.

Slice electrophysiology. Recordings were made from $210-\mu \mathrm{m}$-thick coronal brainstem slices prepared from P16-P22 GIN mice and their nontransgenic littermates. The transgene had no apparent effect on any measured parameter and, therefore, the data from these two groups were pooled. Slices were cut and then incubated for $1 \mathrm{~h}$ in $34^{\circ} \mathrm{C}$ ACSF composed of (in mM) $130 \mathrm{NaCl}, 3 \mathrm{KCl}, 2.4 \mathrm{CaCl}_{2}, 1.3 \mathrm{MgSO}_{4}, 1.2 \mathrm{KH}_{2} \mathrm{PO}_{4}, 20$ $\mathrm{NaHCO}_{3}, 3 \mathrm{Na}-\mathrm{HEPES}$, and 10 glucose, bubbled with $5 \% \mathrm{CO}_{2} / 95 \% \mathrm{O}_{2}$, osmolality $\sim 305 \mathrm{mOsm}$. All recordings were made at $33-34^{\circ} \mathrm{C}$ with ACSF that was supplemented with $10 \mu \mathrm{M}$ 6,7-dinitroquinoxaline-2,3dione (DNQX) or $10 \mu \mathrm{M}$ 2,3-dihydroxy-6-nitro-7-sulfonyl-benzo[f] quinoxaline (NBQX) to block excitatory activity. To examine the pharmacology of synaptic transmission between cartwheel cells, $500 \mathrm{~nm}$ strychnine and $20 \mu \mathrm{M}$ 2-(3-carboxypropyl)-3-amino-6-(4-methoxyphenyl)-pyridazinium bromide (SR95531) were added directly to the bath ACSF. Electrodes (2-4 M $\Omega$ ) were filled with an intracellular solution composed of (in mM) $113 \mathrm{~K}$-gluconate, 9 HEPES, $4.5 \mathrm{MgCl}_{2}, 0.1$ EGTA, 14 Tris $_{2}$-phosphocreatine, $4 \mathrm{Na}_{2}$-ATP, and 0.3 Tris-GTP, with osmolality brought to $\sim 290 \mathrm{mOsm}$ with sucrose and $\mathrm{pH}$ adjusted to 7.25 with $\mathrm{KOH}$. To improve IPSC detection, $E_{\mathrm{Cl}}$ was increased in some experiments by adding $6.6 \mathrm{~mm} \mathrm{KCl}$ to the intracellular solution in place of an equal amount of K-gluconate. Data were corrected for a $13 \mathrm{mV}$ junction potential.

Neurons were visualized with infrared videomicroscopy and gradient contrast optics (Dodt et al., 2002). A mercury lamp and an enhanced GFP (EGFP) filter set were used to view EGFP-expressing neurons. Data were acquired at $20-50 \mathrm{kHz}$ and low-pass filtered at $3-10 \mathrm{kHz}$ using a MultiClamp 700B amplifier, Digidata 1322A digitizer, and Clampex 9 software. In voltage-clamp recordings, cells were held at -73 to $-93 \mathrm{mV}$ and series resistance $(<30 \mathrm{M} \Omega)$ was usually $80 \%$ compensated. In currentclamp recordings, current was injected to maintain the membrane potential near $-78 \mathrm{mV}$ and bridge balance and pipette capacitance neutralization were set and adjusted throughout the experiment. Except where noted, action potentials were elicited with square current pulses in current clamp.

Chemicals. Strychnine, SR95531, DNQX, NBQX, and DL-APV were from Ascent Scientific. All others were from Sigma-Aldrich.

Electrophysiological data analysis. Data were analyzed using Clampfit 9 and custom algorithms written in Igor Pro (Wavemetrics). Each spikelet in a complex spike that produced an IPSC was counted as a transmission success; spikelets that did not produce an IPSC were counted as failures. To correlate spikelet properties with transmission probabilities, spikelets were first sorted into groups on the basis of whether they produced transmission successes or failures. The data for these two groups were binned, and for each bin transmission probability $=$ successes $/$ (successes + failures). Transmission probabilities were then fit with a sigmoidal function of the form $y=1 /\left(1+\exp \left(-\left(x-X_{\text {half }}\right) / k\right)\right)$. Synaptic jitter was equal to the SD of the presynaptic spike to IPSC latency (from peak of 
presynaptic spike to time of $20 \%$ rise of IPSC). To compare IPSC areas across pairs, we examined pairs in which we were able to evoke different numbers (e.g., spikelet doublets, triplets, etc.) of postsynaptic IPSCs ( $>10$ trials per condition, $n=9$ pairs). For each pair, the mean area for each IPSC group was calculated and normalized to the mean area for the three-IPSCs group. Data were then averaged across pairs. To simulate EPSPs in current clamp, we examined the time course of spontaneous EPSCs measured in voltage clamp. EPSCs were well fit by the double exponential function $\operatorname{EPSC}(t)=A m p\left(1-e^{-t / \tau_{\text {rise }}}\right)\left(e^{-t / \tau_{\text {decay }}}\right)$, where Amp was variable and corresponds to the amplitude of the EPSC, $\tau_{\text {rise }}=$ $0.30 \pm 0.05 \mathrm{~ms}$, and $\tau_{\text {decay }}=1.59 \pm 0.13 \mathrm{~ms}$. This function was used to generate stimulus files that directed the current clamp to inject current with an EPSC-like waveform. Amp was gradually increased until the EPSC-like stimulus was large enough to reliably evoke simple spikes or complex spikes (two to four spikelets per stimulus). Significant differences $(p<0.05)$ were detected with $t$ tests or one-way ANOVAs with Tukey's post hoc test. Data are mean \pm SEM except where noted.

Two-photon imaging and analysis. For imaging experiments, slices were prepared from P17-P22 ICR mice (Harlan) using the procedures detailed above. Experiments were performed at $32-34^{\circ} \mathrm{C}$. EGTA was omitted from the internal solution and replaced with $20 \mu \mathrm{M}$ Alexa Fluor 594 hydrazide and $200 \mu \mathrm{M}$ Fluo-5F (bouton imaging experiments) or 200 $\mu \mathrm{M}$ Fluo-4FF (somatodendritic imaging experiments; Invitrogen). A Ti: sapphire pulsed laser (Chameleon Ultra II; Coherent) tuned to $810 \mathrm{~nm}$ powered a Prairie Technologies Ultima two-photon imaging system. Laser intensity was controlled with an electro-optical modulator (350-80 LA; Conoptics). Cells were imaged with a $60 \times, 0.9$ numerical aperture (NA) objective (Olympus). Both epifluorescence and transfluorescence signals were captured (the latter using a 1.4 NA oil-immersion condenser and custom substage detectors). Fluorescence was split into red (R; Alexa 594) and green (G; Fluo-5F, Fluo-4FF) channels using dichroic mirrors and bandpass filters (epifluorescence: 575 DCXR, HQ525/70, HQ607/ 45; transfluorescence: T560LPXR, ET510/80, ET620/60; Chroma) and focused on multialkali photomultiplier tubes (R9110; Hamamatsu). Processes were imaged in line-scan mode $(2.2 \mathrm{~ms} / \mathrm{line}$, including mirror flyback), and complex spike, simple spike, and spike train stimuli were interleaved. Data are presented as averages of 20-40 (for dendritic recordings) or 60-80 (for axonal recordings) events per site and expressed as $100 \times(G / R) /(G / R)_{\max }$, where $(G / R)_{\max }$ was the maximal fluorescence in saturating $\mathrm{Ca}^{2+}(2 \mathrm{mM})$ (Yasuda et al., 2004). Electrophysiological data were recorded at $5 \mathrm{kHz}$ and filtered at $2 \mathrm{kHz}$ using an Axopatch $200 \mathrm{~B}$ amplifier and acquired with an ITC-18 interface (Instrutech) using custom software written in Igor Pro. Spikes were evoked by somatic current injection (complex spikes: 3-500 pA, $10 \mathrm{~ms}$; simple spikes: $1 \mathrm{nA}, 2 \mathrm{~ms}$ ) or by stimulus electrode excitement of parallel fiber inputs in the presence of $500 \mathrm{nM}$ strychnine and $20 \mu \mathrm{M}$ SR95531 (NBQX was omitted for this experiment). Hyperpolarizing steps were often injected to suppress complex spiking where appropriate ( -2 to $-500 \mathrm{pA}, 10 \mathrm{~ms}$ duration, $2 \mathrm{~ms}$ delay from depolarizing onset). IPSPs were evoked via stimulus electrode excitement of inhibitory inputs in the presence of $10 \mu \mathrm{M}$ NBQX and 100 $\mu \mathrm{M}$ DL-APV.

\section{Results}

We used dual whole-cell recordings of synaptically coupled pairs of cartwheel cells to examine the fidelity with which somatic complex spikes produce postsynaptic responses. Slices were prepared from transgenic GIN mice or from their nontransgenic littermates. In GIN mice, the promoter for the GABA synthetic enzyme GAD67 drives EGFP expression in a subset of interneurons (Oliva et al., 2000). Most EGFP-labeled cells in the outer layers of the DCN were cartwheel cells, as confirmed by their location, their characteristic round somata and spiny dendrites (Fig. 1A) (Wouterlood and Mugnaini, 1984), and their capacity to generate complex spikes (Zhang and Oertel, 1993; Manis et al., 1994). This EGFP labeling facilitated the localization of cartwheel cells and was particularly useful for identifying pairs of nearby cartwheel cells.
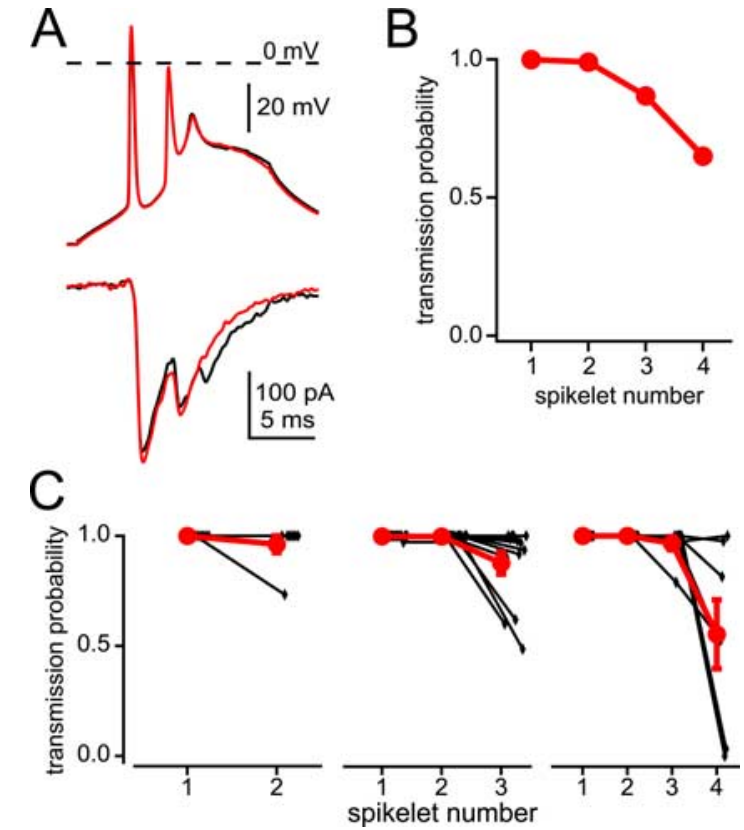

Figure 2. Complex spike transmission failures. $\boldsymbol{A}$, In two trials from one cartwheel cell pair, current injection induced the presynaptic cell to fire complex spikes comprised of three spikelets. In one trial, each spikelet in the complex spike yielded an IPSC (black trace). In the other, the third spikelet failed to produce an IPSC (red trace; $V_{\text {hold }}=-88 \mathrm{mV}$ ). B, Across 1435 trials from 27 cartwheel cell pairs, the number of instances when spikelets at a given position within a complex spike resulted in transmission successes was counted and divided by the total number of spikelets at that position. The resulting value provides an estimate of the overall transmission probability for each spikelet within a complex spike. C, Pairs were sorted by the number of spikelets in the presynaptic complex spike. For each pair, the transmission probability of each spikelet was calculated (black data). Data were then averaged across pairs (red data). Regardless of whether the complex spike consisted of two, three, or four spikelets, the final spikelet accounted for most transmission failures.

If a complex spike initiated by a current pulse in one cartwheel cell elicited IPSCs in another cartwheel cell, we classified that pair as synaptically coupled. Of the 152 cartwheel cell pairs from which we recorded, 62 pairs were synaptically coupled, indicating a minimal probability of connectivity of $41 \%$. Synaptic transmission between cartwheel cells appeared to be predominately glycinergic, as the glycine receptor antagonist strychnine blocked cartwheel cell to cartwheel cell IPSCs by $\sim 85 \%$. The $\mathrm{GABA}_{\mathrm{A}}$ receptor antagonist SR95531 (gabazine) blocked the remaining current (Fig. $1 B, C$ ). The finding that cartwheel cells corelease GABA is consistent with our observation that the GAD67 promoter drives EGFP expression in these cells in GIN mice, and with previous studies (Mugnaini, 1985; Kolston et al., 1992; Gates et al., 1996).

\section{Spikelet transmission failures}

Most complex spikes consisted of a large initial spikelet followed by one to three smaller spikelets. The early spikelets in a complex spike almost always led to a postsynaptic response, but later spikelets frequently failed to do so (Fig. 2). Across a population of 1435 trials from 27 cartwheel cell pairs, the probability that the first or second spikelet would produce an IPSC was $>98 \%$. For the third spikelet, the probability dropped to $87 \%$, and for the fourth, to $65 \%$ (Fig. $2 \mathrm{~B}$ ). When data were sorted according to pairs in which the presynaptic cell fired complex spikes with two, three, or four spikelets, it became clear that most transmission failures occurred at the final spikelet (Fig. 2C).

This differs from cerebellar Purkinje cells, in which the second 


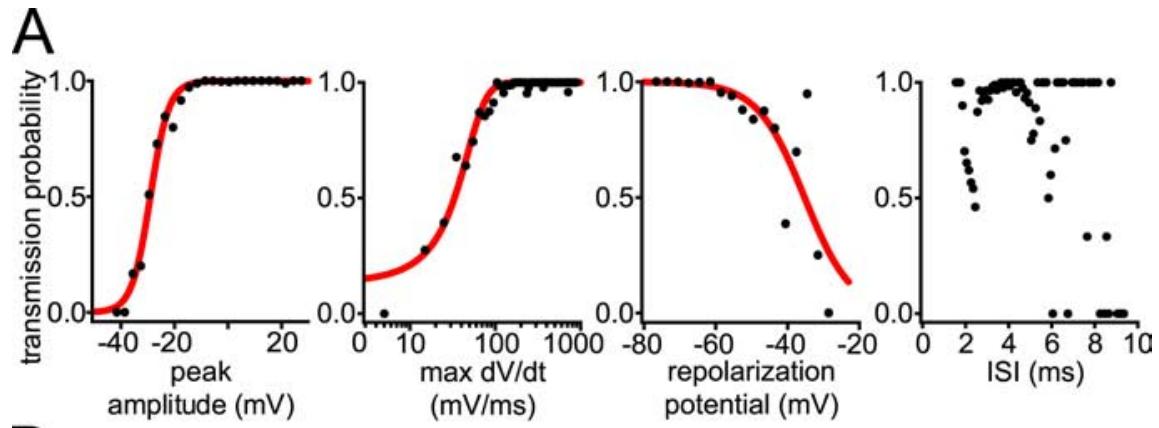

8
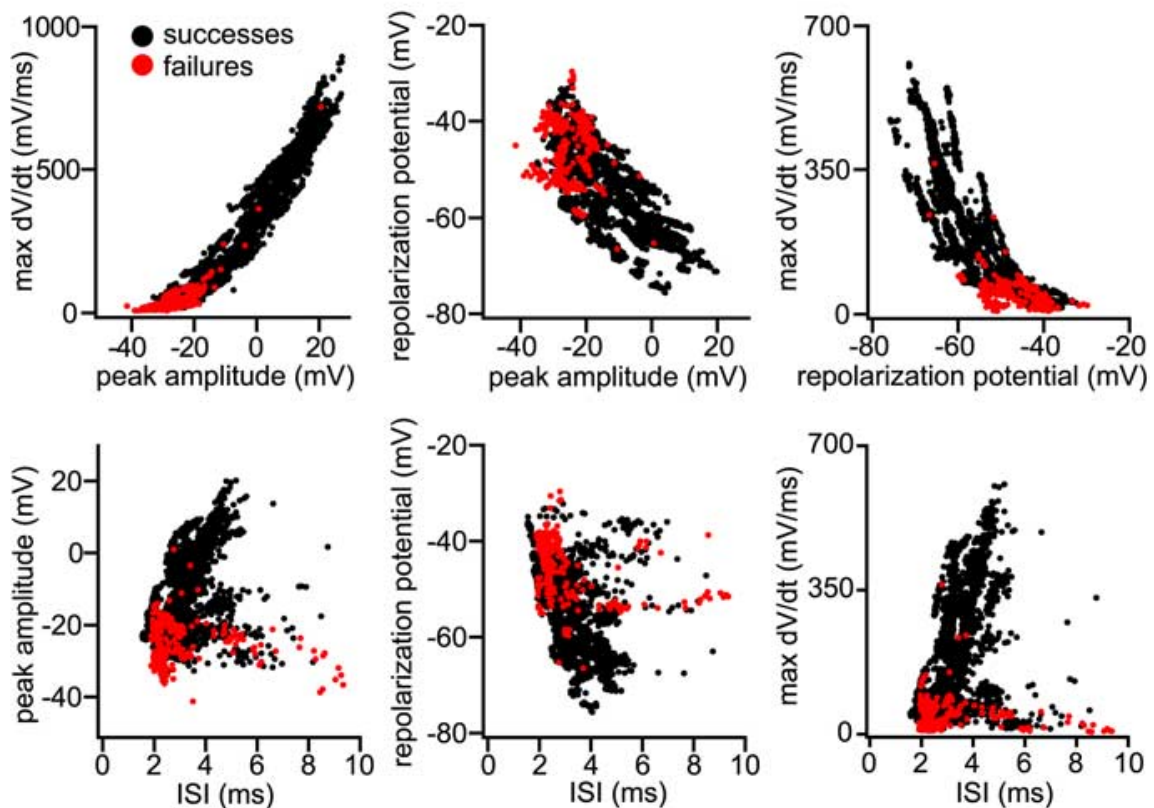

Figure 3. Correlations between spikelet properties and transmission probability. $\boldsymbol{A}$, The absolute peak amplitude, maximal rate of rise, and repolarization potential of spikelets correlated well with the probability that a spikelet would elicit an IPSC and were well fit with a sigmoidal function. Fit parameters are as follows: peak amplitude $-V_{\text {half }}=-29 \mathrm{mV}, k=3.5 \mathrm{mV}$; maximal rate of rise $-d V / d t_{\text {half }}=33 \mathrm{mV} / \mathrm{ms}, k=18 \mathrm{mV} / \mathrm{ms}$; repolarization potential $-V_{\text {half }}=-35 \mathrm{mV}, k=-6.6 \mathrm{mV}$. ISI values did not correlate with transmission probability and could not be fit with a sigmoidal function. $\boldsymbol{B}$, Comparisons between spikelet properties. Black dots represent spikelets that produced IPSCs. Red dots represent spikelets that failed to produce IPSCs. The plots in the top row reveal that most transmission failures correspond to spikelets that were small, slow to rise, and preceded by depolarized membrane potentials. Correlation coefficients are as follows: maximum $d V / d t$ versus peak amp, $r=0.97$; repolarization potential versus peak amp, $r=-0.75$; maximum $d V / d$ t versus repolarization potential, $r=-0.82$; peak amp versus ISI, $r=0.33$; repolarization potential versus ISI, $r=-0.35$; maximum $d V / d t$ versus $I S I, r=0.36$.

spikelet in complex spikes was the most failure prone (Khaliq and Raman, 2005; Monsivais et al., 2005). To investigate the basis of this difference, we examined the complex spike waveform, testing several properties of individual spikelets for correlations between spikelet parameters and transmission successes or failures. Spikelet peak amplitude and maximal rate of rise were positively correlated with the probability that a spikelet would yield an IPSC (Fig. 3A). For spikelets after the initial spikelet in a complex spike, the maximal extent of membrane repolarization preceding the spikelet (repolarization potential) was negatively correlated with transmission probability. Comparisons between spikelet properties revealed that peak amplitude, maximal rate of rise, and the preceding repolarization potential covaried and are reasonable predictors of transmission success (Fig. $3 B$ ). Interestingly, the interspikelet interval (ISI) did not correlate with transmission probability, nor did it covary with any of the other spikelet properties we measured. There did appear to be a trend toward failures occurring at low ISI values (Fig. 3B, bottom, clus- ters of failures between 2 and 4 ms ISI), but a number of failures were observed when ISI values were quite large. It is likely that the slow depolarization underlying the complex spike obscured the expected relationship between ISI and spikelet transmission probability, such that the repolarization potential preceding a spikelet exerted greater influence on the transmission probability of the subsequent spikelet than did the ISI. For example, a spikelet preceded by a short ISI and a fairly negative repolarization potential was more likely to elicit an IPSC than a spikelet preceded by a long ISI with a depolarized repolarization potential. Thus, spikelet shape, more than spikelet timing, correlates with transmission probability.

If the amplitude of the underlying slow depolarization contributes significantly to the spikelet shape, then a spike burst separated from the underlying slow depolarization characterizing complex spikes should possess higher transmission fidelity than a regular complex spike. To test this hypothesis, we delivered trains of simple spikes with frequencies matched to ISIs determined for complex spikes in a given presynaptic cell. Because high-frequency stimuli elicited in current-clamped cells almost always evoked complex spikes, simple spike trains were generated in voltage clamp with brief depolarizing voltage steps that were just large enough to reliably evoke escaping spikes $(0.2 \mathrm{~ms}$ steps from $-78 \mathrm{mV}$ to +27 to $+57 \mathrm{mV})$. These simple spike trains produced IPSCs similar to those elicited by complex spikes (Fig. $4 A, B)$. The transmission fidelity of complex-spike-matched simple spike trains was nearly perfect and much higher than that of complex spikes measured within the same cartwheel cell pairs or across a population of pairs (Fig. 4C). Cartwheel cell pairs were also able to transmit to postsynaptic cells simple spike trains elicited at frequencies of up to $500 \mathrm{~Hz}$ (Fig. 4D). Indeed, three of four pairs followed three or more spikes at $500 \mathrm{~Hz}$ before exhibiting transmission failures. These results indicate that the failure of a spikelet to produce an IPSC does not reflect an intrinsic limit on axonal propagation or synaptic release. Rather, they suggest that slow, small spikelets do not always invade the axon.

\section{Failures occur before presynaptic terminals}

Action potentials that invade boutons evoke relatively uniform elevations in local $\mathrm{Ca}^{2+}$ (Geiger and Jonas, 2000; Koester and Sakmann, 2000; Bischofberger et al., 2002; Koester and Johnston, 2005; Brenowitz and Regehr, 2007). $\mathrm{Ca}^{2+}$ transients from trains of action potentials can be predicted by the linear sum of individual spike $\mathrm{Ca}^{2+}$ waveforms, offset by relative spike timing within the train (Koester and Sakmann, 2000; Brenowitz and Regehr, 2007). We used this relationship to test whether spikelet transmission failures occur upstream of presynaptic boutons. Cart- 

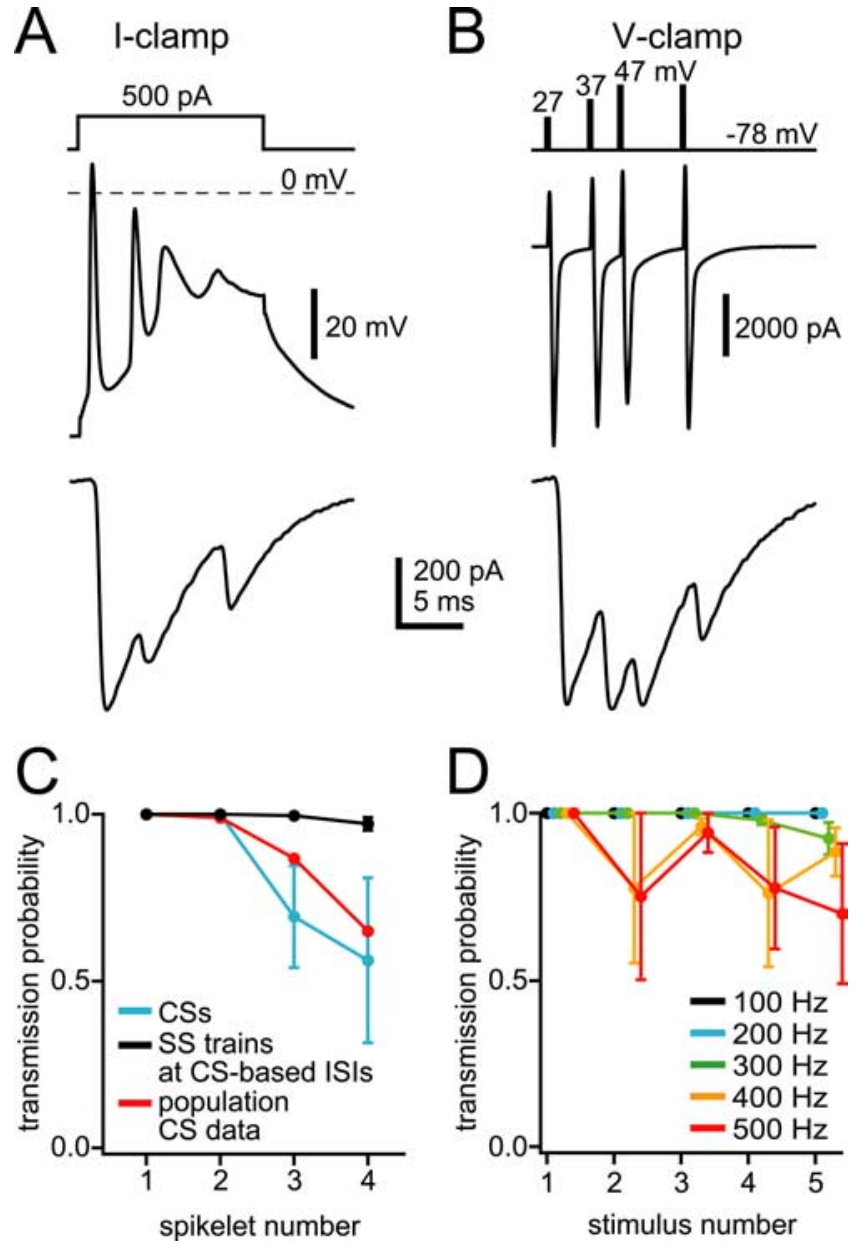

Figure 4. Cartwheel cells transmit trains of simple spikes more reliably than they transmit complex spikes (CSs). $\boldsymbol{A}$, In a synaptically coupled pair of cartwheel cells, a $500 \mathrm{pA}, 15 \mathrm{~ms}$ current injection into the current-clamped presynaptic cell elicited a complex spike that produced IPSCS in the voltage-clamped postsynaptic cell $\left(V_{\text {hold }}=-88 \mathrm{mV}\right)$. $\boldsymbol{B}$, Trains of simple spikes were elicited with ISIs matched to the average ISIs determined for complex spikes within the same pair. To elicit simple spikes, the presynaptic cell was voltage clamped to $-78 \mathrm{mV}$, and $0.2 \mathrm{~ms}$ steps to the indicated voltages elicited action currents that produced IPSCs in the postsynaptic cell (same pair as in $\boldsymbol{A}$ ). $\boldsymbol{C}$, The transmission probabilities of simple spike trains (black) were higher than those for complex spikes (blue; $n=4-5$ ). Population complex spike spikelet transmission probabilities are plotted for reference (red). D, Trains of five simple spikes were elicited in presynaptic cartwheel cells at frequencies of $100-500 \mathrm{~Hz}$. Even at $500 \mathrm{~Hz}$, cartwheel cell pairs were able to follow simple spike trains relatively well $(n=4-5)$. Points are offset for clarity.

wheel cells were current clamped and filled via the patch pipette with the red dye Alexa Fluor $594(20 \mu \mathrm{M})$ and the $\mathrm{Ca}^{2+}$ indicator Fluo-5F $(200 \mu \mathrm{M})$. The axon was imaged with two-photon microscopy as it projected from the soma, and the first one or two en passant boutons encountered were used for subsequent $\mathrm{Ca}^{2+}$ imaging ( $n=5$ cells, 9 boutons, $104 \pm 19 \mu \mathrm{m}$ from soma) (Fig. $5 A$ ). A simple spike elicited in the soma produced a bouton $\mathrm{Ca}^{2+}$ transient whose decay was fit with a single exponential function (Fig. 5B). $\mathrm{Ca}^{2+}$ transients from trains of simple spikes (six spikes at $50 \mathrm{~Hz}$ ) were well fit by the linear sum of single-spike exponentials offset by $20 \mathrm{~ms}$ (Fig. 5C,F); however, complex spikes often evoked sublinear $\mathrm{Ca}^{2+}$ transients (Fig. $5 D$ ). In six of nine boutons, the observed $\mathrm{Ca}^{2+}$ transient was smaller than predicted from the sum of the exponential functions, suggesting that some spikelets failed to invade the bouton (Fig. $5 F$ ). Furthermore, the amplitudes of the $\mathrm{Ca}^{2+}$ transients for all nine boutons were pos- itively correlated with the maximal rate of rise of the final spikelet in the complex spike, with the slowest spikelets yielding the lowest observed/predicted $\Delta G / R$ ratios $(r=0.96)$ (data not shown). This is consistent with our earlier observation that slowly rising spikelets are less likely to be transmitted (Fig. 3). The amplitude of the complex spike $\mathrm{Ca}^{2+}$ transient was always smaller than that evoked by the simple spike train and was always within the linear range of the $\mathrm{Ca}^{2+}$ indicator (Yasuda et al., 2004), thus excluding errors resulting from dye saturation. This result suggests that spikelet transmission failures occur before invading presynaptic terminals, probably at the level of the axon initial segment.

The slow, $\mathrm{Ca}^{2+}$-mediated depolarization underlying the complex spike can be elicited even when $\mathrm{Na}^{+}$channels are blocked by tetrodotoxin (TTX) (Golding and Oertel, 1997; Kim and Trussell, 2007). It is possible that this waveform might propagate into the axon and alter $\mathrm{Ca}^{2+}$ levels in axonal boutons. We examined this possibility and found no change in bouton $\mathrm{Ca}^{2+}$ levels after stimulating cartwheel cells to fire complex spikes in the presence of TTX (Fig. 5E, G), indicating that, as in Purkinje cells, $\mathrm{Ca}^{2+}$ spikes do not propagate (Monsivais et al., 2005).

\section{Reproducibility of postsynaptic responses to complex spikes}

In the analyses thus far, postsynaptic responses to complex spikes have been treated as all-or-nothing events. The information content of a complex spike, however, will depend not only on its ability to elicit IPSCs but also on the temporal fidelity and reproducibility of those IPSCs. Accordingly, we investigated the trialto-trial variability in the postsynaptic responses to complex spikes. An overlay of 15 trials from one cartwheel-to-cartwheel cell pair indicates that the time between a presynaptic spikelet and postsynaptic IPSC is brief (Fig. 6A), whereas a view of the same IPSCs on an expanded time scale demonstrates that there is little variability in the relative timing between presynaptic and postsynaptic events (Fig. 6C). Across 27 pairs, the latency from the peak of the first spike in a presynaptic complex spike to the $20 \%$ rise in the resulting IPSC was $0.58 \pm 0.10 \mathrm{~ms}$ (SD) (Fig. $6 B$ ). Synaptic jitter, a measure of the spread of latency values, was $0.05 \pm 0.02 \mathrm{~ms}$ (SD) (Fig. 6B). The initial postsynaptic response to a presynaptic complex spike therefore occurs rapidly and with a remarkably high degree of temporal precision.

Within cartwheel cell pairs, we routinely observed that IPSCs elicited by presynaptic complex spikes rose to similar peak amplitudes in repeated trials (Fig. 7A). We quantified this by calculating the coefficient of variation $(\mathrm{CV}=\mathrm{SD} /$ mean $)$ of IPSC peak amplitude for each IPSC in a complex IPSC (Fig. 7B). Spikelet transmission failures were either excluded from the data set or included as zero amplitude events. By comparing results from these two conditions, it was evident that transmission failures at the fourth spikelet in a complex spike had a large effect on peak amplitude variability, whereas failures at other spikelet positions did not, probably because failures at earlier positions are less common.

The charge carried by a complex IPSC, as measured by the area under the IPSC, may be a more informative measure than IPSC peak amplitude of the overall effects of a complex spike on the excitability of the postsynaptic cell. We measured the area under IPSCs resulting from simple spikes and from complex spikes with two to four spikelets. Although a particular presynaptic cartwheel cell tended to produce complex spikes with a consistent number of spikelets, our data set included nine pairs in which the presynaptic cell produced complex spikes with 2-3 or 3-4 spikelets. From this data set, we found that three IPSCs were needed to double the charge resulting from a single IPSC, indicating that 


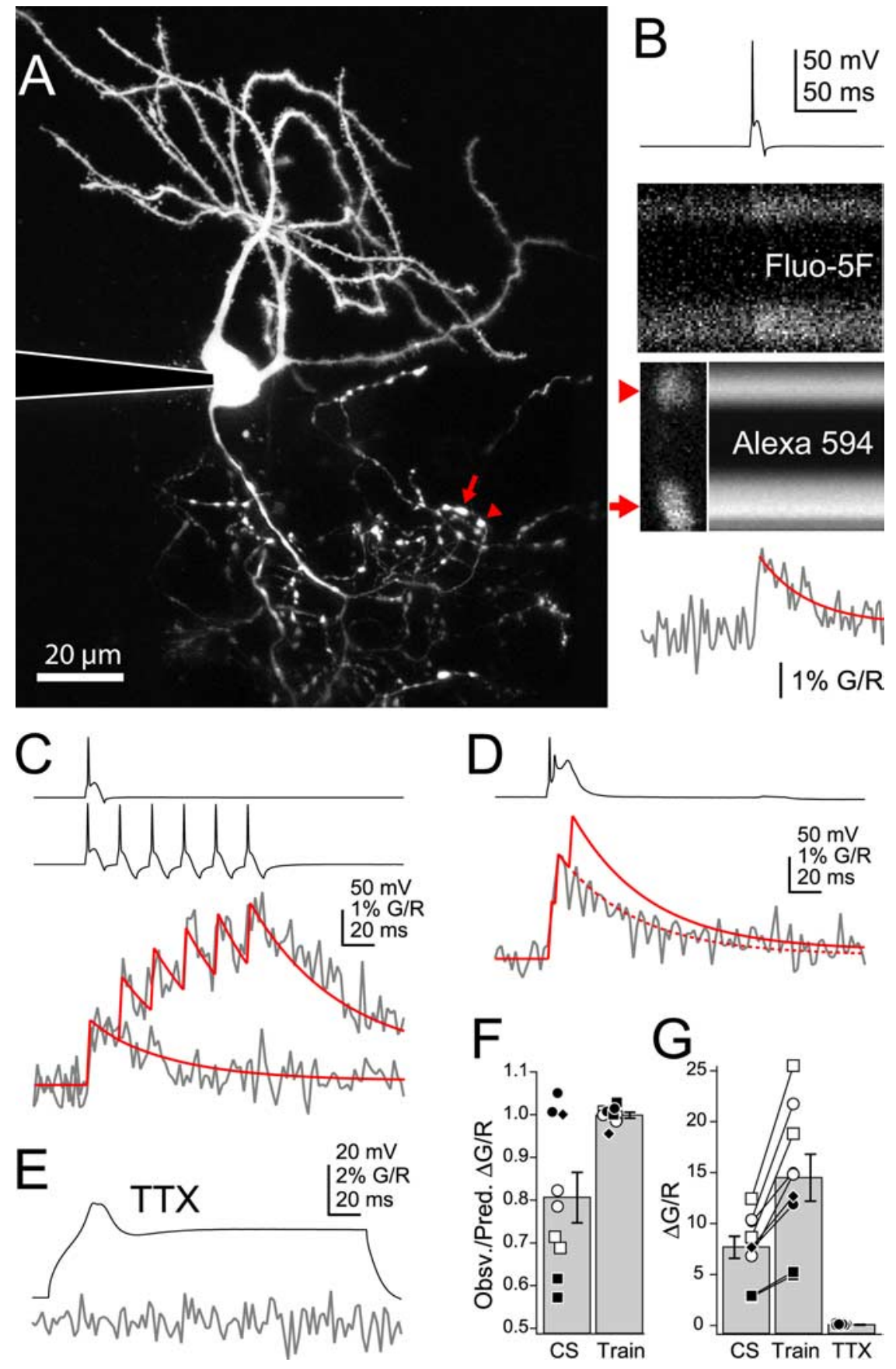

Figure 5. Two-photon $\mathrm{Ca}^{2+}$ imaging of presynaptic boutons. $\boldsymbol{A}$, Maximum intensity photomontage of a cartwheel cell. Arrow and arrowheads indicate the first visible en passant boutons along left axonal branch. $\boldsymbol{B}$, Somatically-evoked simple spikes (top) elicit increased Fluo-5F ( $\mathrm{Ca}^{2+}$ sensitive; green) with no change in Alexa 594 ( $\mathrm{Ca}^{2+}$ insensitive; red). Hyperpolarizing current was injected immediately after simple spikes to prevent complex spikes. Bottom, Green fluorescence divided by red ( $G / R$; gray) from the top bouton (arrowhead) fit with a single exponential (red). $C, \mathrm{Ca}^{2+}$ transients from a train of six simple spikes $(50 \mathrm{~Hz})$ were fit with the linear sum of six exponential decays derived from a single spike fit. $\boldsymbol{D}, \mathrm{Ca}^{2+}$ transient from a complex spike with three spikelets. Red solid line, Expected fit from three spikelets. Red dashed line, Expected fit from first two spikelets. $E$, The $\mathrm{Ca}^{2+}$ component of a complex spike, isolated with $\Pi \mathrm{TX}$, did not elicit an axonal $\mathrm{Ca}^{2+}$ transient. $F, 0$ bserved $G / R$ divided by expected $G / R$ for complex spikes with three spikelets and trains of six simple spikes. Symbols represent the five cells from which the data were taken. Note the correlation in $\mathrm{Ca}^{2+}$ transients among boutons measured from individual cells. G, Peak G/R amplitude of complex spikes, trains, and complex spikes in TTX. Lines connect recordings from the same bouton. Error bars are SEM. $n=5$ cells, 9 boutons.

IPSCs after the initial IPSC yield sublinear increases in total charge (Fig. 7C). This is because successive IPSCs are smaller. This sublinearity, combined with random amplitude fluctuation of each event from trial to trial, had striking effects on minimizing variability in charge transfer and on the effects of spikelet failures.
Indeed, the variability of IPSC charge was far lower than the variability of IPSC peak amplitudes, with CV values of $<20 \%$, and was constant as the number of spikelets contributing to the complex IPSC increased from one to four (Fig. 7D). When complex IPSCs containing transmission failures were included in the data set, the failures did not decrease the average charge carried by the complex IPSCs or increase the CV. These results suggest that, despite spikelet transmission failures, complex spikes from a given cartwheel cell elicit reproducible charge flux in postsynaptic cells.

\section{Complex spikes inhibit} postsynaptic excitability

Cartwheel cells receive excitatory inputs from parallel fibers that extend through the molecular layer of the DCN. Given a likely scenario in which a synaptically coupled pair of cartwheel cells receives excitatory inputs from separate groups of parallel fibers and each group drives its respective cell to fire, we hypothesized that a presynaptic complex spike would more effectively inhibit firing in the postsynaptic cell than a presynaptic simple spike. To test this, we attempted to selectively stimulate one cartwheel cell in a pair by placing a stimulus electrode at several nearby points in the molecular layer. With this approach, we were unable to stimulate parallel fibers synapsing onto one cartwheel cell without also stimulating parallel fibers synapsing onto neighboring cartwheel cells (data not shown), presumably because of the high density of parallel fibers in the molecular layer and the relatively large area that a stimulating electrode excites. We therefore mimicked cell-selective parallel fiber input by injecting depolarizing current into current-clamped cartwheel cells using an EPSC-like waveform (see Materials and Methods). The amplitude of these currents was set so as to reliably elicit a simple spike or complex spike in the presynaptic cell and a complex spike in the postsynaptic cell. Stimuli were delivered to the postsynaptic cell at a fixed time and presynaptic stimuli were delivered within a window $\pm 20 \mathrm{~ms}$ from the onset of the postsynaptic stimulus. Presynaptic simple spikes and complex spikes reliably inhibited postsynaptic complex spikes when they were evoked at the same time as the postsynaptic stimulus (Fig. $8 A, B$ ). When presynaptic stimuli were offset in time, we found that complex spikes inhibited postsynaptic firing throughout a time window at least $4 \mathrm{~ms}$ broader than that generated by presynaptic simple spikes (Fig. 8C). Presynaptic simple spikes and complex spikes were both able to reduce the number of spikelets in the postsyn- 


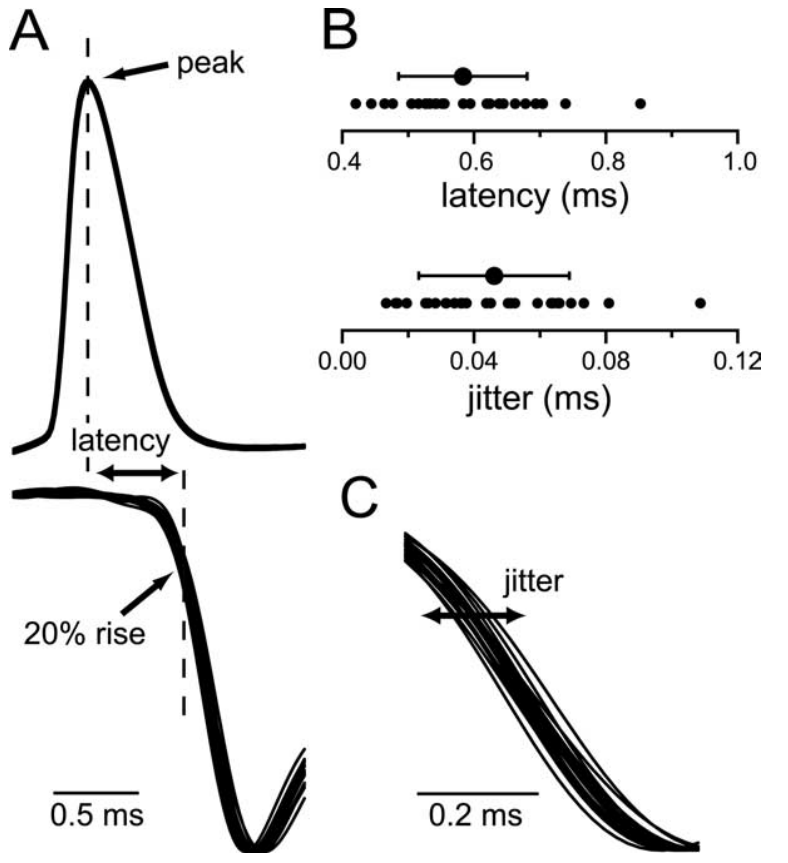

Figure 6. Synaptic transmission between cartwheel cells occurs with a brief latency and low jitter. $\boldsymbol{A}$, Latency was measured from the peak of the initial spikelet in presynaptic complex spikes (top) to the $20 \%$ rise in the first IPSC detected in the postsynaptic cell (bottom). Fifteen sweeps are shown $\left(V_{\text {hold }}=-83 \mathrm{mV}\right.$ ). $\boldsymbol{B}$, Latency and jitter measurements from 27 pairs (small dots). Mean values are plotted $\pm S D$ (large dots with error bars). $C$, An expanded view of the IPSCS shown in $A$. Note the low amount of jitter across 15 trials.

aptic complex spike, often converting complex spikes into simple spikes. We did not observe any instances in which presynaptic firing blocked the firing of the initial spikelet in the postsynaptic cell. This suggests that the response of a cartwheel cell to parallel fiber input that is just above the threshold for complex spike initiation is highly dependent on whether or not a neighboring cartwheel cell provides coincident inhibitory input. Thus, individual cartwheel cells may exert a strong influence over the generation of complex spikes in neighboring cartwheel cells.

Inhibition that can convert a complex spike to a simple spike might influence postsynaptic excitability in multiple ways. For example, in cerebellar Purkinje cells, complex spikes induce $\mathrm{Ca}^{2+}$ influx throughout the dendritic arbor (for review, see Schmolesky et al., 2002). Moreover, spike-timing dependent synaptic plasticity in cartwheel cell dendrites is strongly dependent on postsynaptic $\mathrm{Ca}^{2+}$ levels (Tzounopoulos et al., 2004, 2007). We therefore compared the $\mathrm{Ca}^{2+}$ transients produced by simple spikes and complex spikes in cartwheel cell dendrites. Complex spikes were elicited by somatic current injection and by stimulation of parallel fiber inputs with a stimulus electrode placed in the molecular layer (Fig. 8D). The resulting complex spikes generated $\mathrm{Ca}^{2+}$ transients in the soma and throughout the dendrites (Fig. 8E). Across several cartwheel cells, complex spikes repeatedly elicited large $\mathrm{Ca}^{2+}$ transients in the somatodendritic compartment, whereas simple spikes, elicited by somatic current injection, produced little $\mathrm{Ca}^{2+}$ influx (Fig. $8 F$ ). The magnitude of complex-spike-generated $\mathrm{Ca}^{2+}$ transients was relatively insensitive to the method used for evoking the complex spike $\left(r^{2}=0.90\right.$, linear regression of somatically evoked vs synaptically evoked complex spike $\mathrm{Ca}^{2+}$ transients), suggesting that complex spikes evoked by somatic current injection mimic the somatodendritic $\mathrm{Ca}^{2+}$ flux produced by synaptically evoked complex spikes.

We next examined whether inhibition that converts a com-
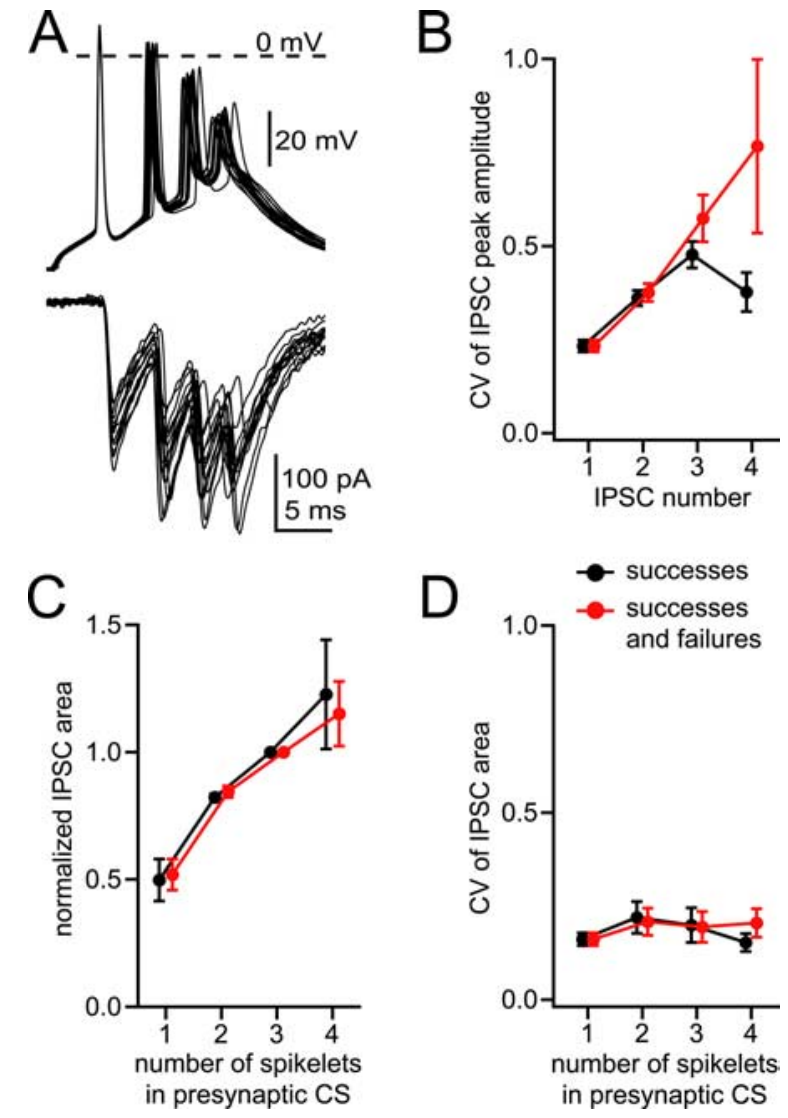

Figure 7. Variability in the peak amplitude and area of IPSCs elicited by complex spikes (CSs). $A$, An example of 15 trials from one pair in which IPSCS (bottom) were elicited by presynaptic complex spikes (top). Note how the IPSC peak amplitudes and the total area under the IPSCs vary from trial to trial $\left(V_{\text {hold }}=-78 \mathrm{mV}\right)$. B , The peak amplitudes of each IPSC in the postsynaptic response to a complex spike were measured. Across multiple trials from 27 pairs, the $\mathrm{CV}$ of IPSC peak amplitudes was calculated (SD/mean). When a presynaptic spikelet failed to elicit an IPSC, that event was either ignored (black data points) or counted as an IPSC with an amplitude of 0 (red data points). Counting transmission failures as zero amplitude events increased the variability of peak amplitudes at the fourth IPSC. C, The postsynaptic charge produced by complex spike elicited IPSCs was determined by measuring the area under IPSCS. Instances where one or more spikelets failed to elicit an IPSC were either excluded (black data) or included (red data) in the data set. Data were normalized to the average area under postsynaptic responses comprised of three IPSCs ( $n=9$ pairs). $\boldsymbol{D}$, Variability of the data shown in C as measured by the CV. Transmission failures do not alter the average variability of the postsynaptic charge produced by an IPSC.

plex spike to a simple spike reduces somatodendritic $\mathrm{Ca}^{2+}$ transients. Complex spikes were generated through somatic current injection and IPSPs were evoked via a stimulus electrode placed in the molecular layer. When current was injected to elicit a complex spike, large $\mathrm{Ca}^{2+}$ transients were observed in the soma and dendrites (Fig. 8G,H). When an IPSP was evoked at the same time as the somatic current injection or 2 ms preceding the somatic current injection, the complex spike stimulus yielded a simple spike and a markedly smaller $\mathrm{Ca}^{2+}$ transient. Across five cells, simple spikes produced by the combination of a complex spike stimulus and an IPSP resulted in $\mathrm{Ca}^{2+}$ transients that were significantly smaller than the $\mathrm{Ca}^{2+}$ transients from full complex spikes $(p<0.01)$. Furthermore, these $\mathrm{Ca}^{2+}$ transients were not significantly different from those generated by simple spikes that were evoked by brief somatic current injection followed by a hyperpolarizing current to prevent complex spike firing ( $p=$ 0.14 ). These results indicate that blockade of complex spike firing 

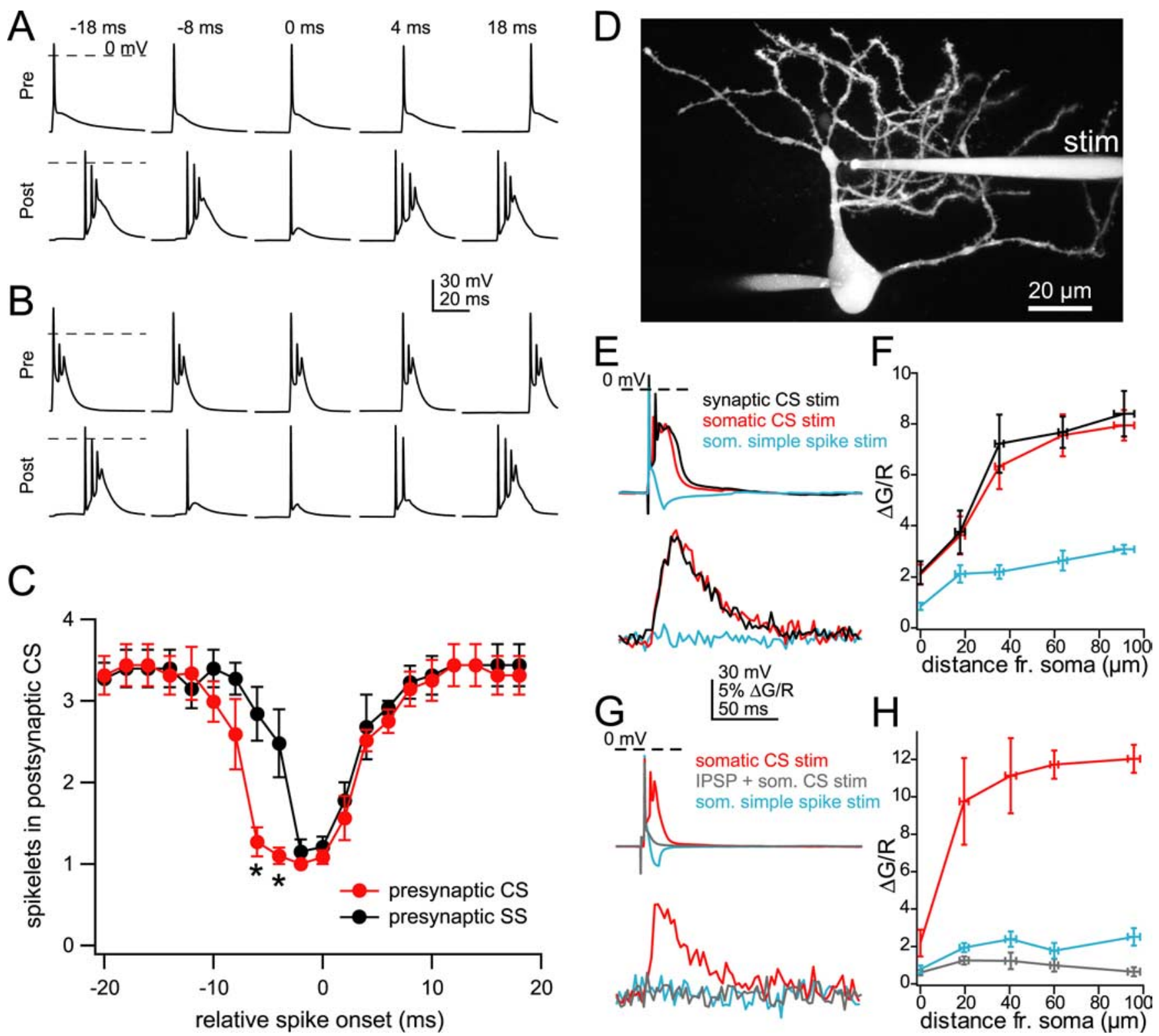

Figure 8. Inhibition of complex spikes (CSs) and dendritic $\mathrm{Ca}^{2+}$ transients. $\boldsymbol{A}, \boldsymbol{B}$, Current-clamped cells were stimulated with an EPSC-like waveform. In the presynaptic cell, the stimulus amplitude was calibrated to reliably elicit a simple spike ( $\boldsymbol{A}$, top row) or a complex spike ( $\boldsymbol{B}$, top row). In the postsynaptic cell, the stimulus amplitude was calibrated to reliably elicit a complex spike (bottom rows). The postsynaptic stimulus was delivered at time 0 , whereas the presynaptic stimuli were delivered at times ranging from $20 \mathrm{~ms}$ before to $18 \mathrm{~ms}$ after the postsynaptic stimulus. Shown are trials in which the presynaptic stimulus was given $-18,-8,0,4$, and 18 ms before/after the postsynaptic stimulus. The dashed lines indicate $0 \mathrm{mV}$. C, Presynaptic complex spikes inhibited the firing of postsynaptic complex spikes over a 4 ms broader time window than did presynaptic simple spikes $\left({ }^{*} p<0.05\right.$, paired $t$ test; $n=4$ pairs). $\boldsymbol{D}$, Maximum intensity projection of a cartwheel cell showing stimulus electrode placed near the dendritic arbor in the molecular layer. $\boldsymbol{E}$, Complex spikes (top) evoked by parallel fiber stimulation (black) and by somatic currentinjection (red) drove $\mathrm{Ca}^{2+}$ transients (bottom) in cartwheel cell dendrites assayed with Fluo-4FF. Simple spikes evoked by brief somatic current injection followed by a hyperpolarizing current produced small $\mathrm{Ca}^{2+}$ transients (cyan). Calibration applies to $\boldsymbol{E}$ and $\mathbf{G} . \boldsymbol{F}$, $\mathrm{Ca}^{2+}$ transient amplitude for complex spikes evoked synaptically and somatically and simple spikes evoked somatically in cartwheel cell dendrites, based on dendritic distance from the center of the soma. Somatic $\mathrm{Ca}^{2+}$ transients are shown in the $0 \mu$ m distance bin. $n=7$ cells, 4-11 sites per distance bin. G, Somatic current injection evoked a complex spike (top, red) and a dendritic $\mathrm{Ca}^{2+}$ transient (bottom), but when an IPSP was evoked $2 \mathrm{~ms}$ before the complex spike stimulus, a simple spike was fired (gray) and the $\mathrm{Ca}^{2+}$ transient was reduced to a magnitude comparable with that generated by a somatically evoked simple spike (cyan). $\boldsymbol{H}, \mathrm{Ca}^{2+}$ transient amplitude for complex spikes and simple spikes generated by somatic current injection and for simple spikes produced by inhibition delivered coincident or $2 \mathrm{~ms}$ before somatic current injection that would otherwise evoke a complex spike. Error bars are SEM. $n=5$ cells, $5-16$ sites per distance bin.

by neighboring cartwheel cells must yield a sharp reduction in $\mathrm{Ca}^{2+}$ signaling throughout the dendritic arbor.

\section{Discussion}

The cartwheel cell, with its relatively short axon and high connectivity rate, offered a unique opportunity to probe the impact of complex spikes on inhibitory synaptic transmission. By recording from synaptically coupled pairs of cartwheel cells, we were able to correlate several aspects of spikelet size and shape with the amplitude and timing of postsynaptic events. We found that a high-frequency burst of spikes can enter the axon, efficiently propagate to nerve terminals, and be transmitted as IPSCs with a high degree of temporal precision. Failures to propagate all components of the complex spike appear to originate at invasion of the axon, as axons and terminals were able to sustain transmission of very high-frequency simple spikes. Remarkably, when failures occurred, they had no impact on the trial-to-trial varia- 
tion in inhibitory charge. We believe this is the result of the characteristics of IPSC summation: because individual IPSCs appear to saturate in amplitude, later events contribute relatively less charge to the IPSC complex, so that their periodic failure has little impact on inhibition.

\section{Mechanisms underlying transmission failures}

The failure of later spikelets in complex spikes to elicit a postsynaptic response differs substantially from the situation in cerebellar Purkinje cell complex spikes, where the second spikelet was the most prone to propagation failures measured in the axon (Khaliq and Raman, 2005; Monsivais et al., 2005). In both cartwheel cells and Purkinje cells, spikelets that were small and slow to rise generated most transmission failures (Khaliq and Raman, 2005; Monsivais et al., 2005). In cartwheel cells, the extent to which the membrane potential repolarized between spikelets corresponded with the probability that the next spikelet would yield an IPSC (repolarization potential was not examined in Purkinje cells). These results suggest that transmission failures occurred when $\mathrm{Na}^{+}$channels inactivated, thereby limiting their ability to contribute to subsequent spikelets.

High firing frequencies can also promote the inactivation of voltage-gated ion channels (Debanne, 2004). In cartwheel cells, however, ISIs did not correlate with transmission probability, and cartwheel cell pairs were able to follow short bursts of simple spikes at frequencies up to $500 \mathrm{~Hz}$ and at frequencies matched to those observed within complex spikes. Thus, failures during complex spikes cannot be ascribed to limits on the frequency of axonal spike conduction or on the ability of the synapses to reliably transmit. Two-photon imaging experiments confirmed that transmission failures occur between the soma and proximal axonal boutons. It seems likely therefore that such failures arise at the axon initial segment, probably because of the progressive $\mathrm{Ca}^{2+}$-dependent depolarization that triggers each spikelet (Kim and Trussell, 2007). Purkinje neuron complex spikes do not feature this more gradual rise because they are driven by a large and fast synaptic conductance. Thus, the second spikelet is the smallest, has the shortest ISI, and is the most likely to fail in the axon (Khaliq and Raman, 2005; Monsivais et al., 2005).

Axonal branch points might contribute to action potential propagation failures (Lüscher and Shiner, 1990; Debanne, 2004). Cartwheel cell axons branch profusely (Berrebi and Mugnaini, 1991), and, in our $\mathrm{Ca}^{2+}$ imaging experiments, the most proximal boutons were always found after the first axonal branch point. It is therefore possible that some of the failures we observed occurred at this branch point. The presence of branch points, however, does not necessarily correlate with transmission failures. Two imaging studies in cerebral cortex showed that action potential propagation was quite secure, even when multiple branch points were traversed (Cox et al., 2000; Koester and Sakmann, 2000). Moreover, we found that high-frequency simple spikes propagated well. Thus, our results are most consistent with the hypothesis that transmission failures reflect failures of somatic spikelets to propagate into the axon.

\section{Temporal precision and reproducibility of postsynaptic response to complex spikes}

We found that synapses between cartwheel cells exhibited a high degree of temporal precision, with a latency of $\sim 0.6 \mathrm{~ms}$ and jitter of $\sim 0.05 \mathrm{~ms}$. Compared with other synapses, where similar measurements have been made using conditions comparable with ours (i.e., paired recordings in slice preparations at or near phys- iological temperature), these values appear to be quite small. In cerebellum, synapses formed by Golgi cells have latencies of 1.05$1.1 \mathrm{~ms}$ and jitters of $0.1-0.3 \mathrm{~ms}$ (Dugué et al., 2005). At cortical synapses, reported latencies range from $0.6-4 \mathrm{~ms}$ and jitters from 0.35 to $0.9 \mathrm{~ms}$ (Markram et al., 1997; Feldmeyer et al., 1999, 2002, 2006; Gabernet et al., 2005; Boudkkazi et al., 2007). In the hippocampus, basket cell to pyramidal cell synapses exhibit a latency of $1.46 \mathrm{~ms}$ and jitter of $0.31 \mathrm{~ms}$ (Neu et al., 2007), whereas connections between mossy fiber boutons and CA3 pyramidal neurons had a latency of $0.7 \mathrm{~ms}$ (Geiger and Jonas, 2000). Thus, to our knowledge, cartwheel cell synapses have a latency as brief as any previously measured in these brain regions. This is not surprising, given that cartwheel cell action potentials probably do not travel far before reaching boutons. The jitter at cartwheel cell synapses, however, appears to be exceptionally low. This suggests that $\mathrm{Ca}^{2+}$ influx and vesicular release are tightly coupled in cartwheel cell boutons. Interestingly, inhibitory synapses between cerebellar Purkinje cells appear quite different, with longer synaptic latencies and a higher frequency of transmission failure (Orduz and Llano, 2007).

IPSCs elicited by complex spikes varied little from trial to trial. In the presynaptic bouton, this low variability might reflect high release probability, multivesicular release, and/or multiple release sites (Wadiche and Jahr, 2001; Foster et al., 2002; Oertner et al., 2002; Telgkamp et al., 2004; Christie and Jahr, 2006). Across the synapse, low variability could indicate saturation of receptor binding sites (Wadiche and Jahr, 2001; Foster et al., 2002; Harrison and Jahr, 2003). Surprisingly, transmission failures had little impact on the postsynaptic charge flux elicited by complex spikes. Several factors might contribute to this. First, late IPSCs contributed less charge than the initial IPSC. Second, most transmission failures occurred at the final spikelet. Third, the variability in charge flux from trial to trial even when all spikelets yielded IPSCs might be larger than, and therefore occlude, the variability introduced by occasional transmission failures. Thus, the properties of the cartwheel-to-cartwheel cell synapse seem to compensate for spikelet transmission failures, thereby helping to maintain the identity of complex spikes as they cross the synapse.

\section{Impact of complex spike signaling on postsynaptic excitability}

Using paired recordings of near-neighbor cells, $41 \%$ of cartwheel cells were synaptically coupled. Thus, cartwheel cells mediate feedforward inhibition to principal cells and form a connected network of interneurons. Understanding how one cartwheel cell modulates the excitability of another will be critical to appreciating how this network operates. Previous studies indicated that at least some cartwheel-to-cartwheel cell connections are depolarizing (Golding and Oertel, 1996; Tzounopoulos et al., 2004), but did not indicate how much a presynaptic cell can influence the membrane potential of a postsynaptic cell or how this would differ with simple spikes and complex spikes. We found that presynaptic simple spikes and complex spikes generated IPSPs powerful enough to convert postsynaptic complex spikes to simple spikes. Presynaptic complex spikes, by reliably eliciting multiple IPSPs, inhibited postsynaptic excitability over a broader time window than did simple spikes. Considered in the context of the cartwheel cell network, this capacity to inhibit neighboring cells would stabilize activity within the network, thereby moderating the inhibition forwarded to the output cells of the DCN. It is currently not known whether connections between cartwheel cells control activity selectively within or between isofrequency bands. Thus, interpretation of our work with respect to the DCN 
circuit will require additional analysis of patterns of axonal projections.

The impact of the conversion of complex spike to simple spike firing has a profound effect on $\mathrm{Ca}^{2+}$ signaling in the soma and dendrites of cartwheel cells. Imaging experiments indicated that complex spikes generate $\mathrm{Ca}^{2+}$ transients that extend throughout the dendritic arbor, increasing in size with distance from the soma, whereas individual simple spikes, produced by brief somatic current injection or stronger somatic current injection coincident with an evoked IPSP, generated little increase in dendritic $\mathrm{Ca}^{2+}$ (see also, Molitor and Manis, 2003). Parallel fiber synapses onto cartwheel cells undergo spike-timing-dependent long-term plasticity that is strongly dependent on postsynaptic $\mathrm{Ca}^{2+}$ (Tzounopoulos et al., 2004, 2007). Moreover, dendritic depolarization leads to depolarization-induced suppression of excitability that is dependent on $\mathrm{Ca}^{2+}$-induced release of endocannabinoids. Together, these data suggest a novel function of lateral inhibition in which activity in inhibitory interneurons might regulate induction of synaptic plasticity at a neighbor's excitatory synapses by preventing complex spike generation. The high temporal precision of cartwheel-to-cartwheel cell synapses is therefore well suited to the regulation of spike-timing dependent plasticity. In vivo support for this idea has recently been obtained in the cerebellum-like electrosensory lobe of mormyrid electric fish (Sawtell et al., 2007). There, medium ganglion cells feature two spike types, a fast axon spike and a broad dendritic spike. The latter play an essential role in behaviorally relevant spike-timing-dependent plasticity, are thought to elicit $\mathrm{Ca}^{2+}$ signals throughout the dendrites, and are selectively gated by inhibitory input. Thus, rapid interneuronal control of $\mathrm{Ca}^{2+}$ signals may be a general mechanism for regulation of plasticity in cerebellum-like structures.

\section{References}

Athanassiadis T, Westberg KG, Olsson KA, Kolta A (2005) Physiological characterization, localization and synaptic inputs of bursting and nonbursting neurons in the trigeminal principal sensory nucleus of the rat. Eur J Neurosci 22:3099-3110.

Berrebi AS, Mugnaini E (1991) Distribution and targets of the cartwheel cell axon in the dorsal cochlear nucleus of the guinea pig. Anat Embryol (Berl) 183:427-454.

Berrebi AS, Morgan JI, Mugnaini E (1990) The Purkinje cell class may extend beyond the cerebellum. J Neurocytol 19:643-654.

Bischofberger J, Geiger JR, Jonas P (2002) Timing and efficacy of Ca2+ channel activation in hippocampal mossy fiber boutons. J Neurosci 22:10593-10602.

Boudkkazi S, Carlier E, Ankri N, Caillard O, Giraud P, Fronzaroli-Molinieres L, Debanne D (2007) Release-dependent variations in synaptic latency: a putative code for short- and long-term synaptic dynamics. Neuron 56:1048-1060.

Brenowitz SD, Regehr WG (2007) Reliability and heterogeneity of calcium signaling at single presynaptic boutons of cerebellar granule cells. J Neurosci 27:7888-7898.

Chagnac-Amitai Y, Luhmann HJ, Prince DA (1990) Burst generating and regular spiking layer 5 pyramidal neurons of rat neocortex have different morphological features. J Comp Neurol 296:598-613.

Christie JM, Jahr CE (2006) Multivesicular release at Schaffer collateralCA1 hippocampal synapses. J Neurosci 26:210-216.

Cox CL, Denk W, Tank DW, Svoboda K (2000) Action potentials reliably invade axonal arbors of rat neocortical neurons. Proc Natl Acad Sci U S A 97:9724-9728.

Debanne D (2004) Information processing in the axon. Nat Rev Neurosci 5:304-316.

Debanne D, Guérineau NC, Gähwiler BH, Thompson SM (1997) Actionpotential propagation gated by an axonal $\mathrm{I}(\mathrm{A})$-like $\mathrm{K}+$ conductance in hippocampus. Nature 389:286-289.

Deschênes M, Roy JP, Steriade M (1982) Thalamic bursting mechanism: an inward slow current revealed by membrane hyperpolarization. Brain Res 239:289-293.

Dodt HU, Eder M, Schierloh A, Zieglgänsberger W (2002) Infrared-guided laser stimulation of neurons in brain slices. Sci STKE 2002:PL2.

Dugué GP, Dumoulin A, Triller A, Dieudonne S (2005) Target-dependent use of co-released inhibitory transmitters at central synapses. J Neurosci 25:6490-6498.

Feldmeyer D, Egger V, Lubke J, Sakmann B (1999) Reliable synaptic connections between pairs of excitatory layer 4 neurones within a single "barrel” of developing rat somatosensory cortex. J Physiol 521:169-190.

Feldmeyer D, Lubke J, Silver RA, Sakmann B (2002) Synaptic connections between layer 4 spiny neurone-layer $2 / 3$ pyramidal cell pairs in juvenile rat barrel cortex: physiology and anatomy of interlaminar signalling within a cortical column. J Physiol 538:803-822.

Feldmeyer D, Lubke J, Sakmann B (2006) Efficacy and connectivity of intracolumnar pairs of layer $2 / 3$ pyramidal cells in the barrel cortex of juvenile rats. J Physiol 575:583-602.

Forti L, Pouzat C, Llano I (2000) Action potential-evoked Ca2 + signals and calcium channels in axons of developing rat cerebellar interneurones. J Physiol 527:33-48.

Foster KA, Kreitzer AC, Regehr WG (2002) Interaction of postsynaptic receptor saturation with presynaptic mechanisms produces a reliable synapse. Neuron 36:1115-1126.

Gabernet L, Jadhav SP, Feldman DE, Carandini M, Scanziani M (2005) Somatosensory integration controlled by dynamic thalamocortical feedforward inhibition. Neuron 48:315-327.

Gates TS, Weedman DL, Pongstaporn T, Ryugo DK (1996) Immunocytochemical localization of glycine in a subset of cartwheel cells of the dorsal cochlear nucleus in rats. Hear Res 96:157-166.

Geiger JR, Jonas P (2000) Dynamic control of presynaptic Ca(2+) inflow by fast-inactivating $\mathrm{K}(+)$ channels in hippocampal mossy fiber boutons. Neuron 28:927-939.

Golding NL, Oertel D (1996) Context-dependent synaptic action of glycinergic and GABAergic inputs in the dorsal cochlear nucleus. J Neurosci 16:2208-2219.

Golding NL, Oertel D (1997) Physiological identification of the targets of cartwheel cells in the dorsal cochlear nucleus. J Neurophysiol 78:248-260.

Harris KD, Hirase H, Leinekugel X, Henze DA, Buzsáki G (2001) Temporal interaction between single spikes and complex spike bursts in hippocampal pyramidal cells. Neuron 32:141-149.

Harrison J, Jahr CE (2003) Receptor occupancy limits synaptic depression at climbing fiber synapses. J Neurosci 23:377-383.

Ivanova A, Yuasa S (1998) Neuronal migration and differentiation in the development of the mouse dorsal cochlear nucleus. Dev Neurosci 20:495-511.

Jung HY, Staff NP, Spruston N (2001) Action potential bursting in subicular pyramidal neurons is driven by a calcium tail current. J Neurosci 21:3312-3321.

Khaliq ZM, Raman IM (2005) Axonal propagation of simple and complex spikes in cerebellar Purkinje neurons. J Neurosci 25:454-463.

Kim Y, Trussell LO (2007) Ion channels generating complex spikes in cartwheel cells of the dorsal cochlear nucleus. J Neurophysiol 97:1705-1725.

Koester HJ, Johnston D (2005) Target cell-dependent normalization of transmitter release at neocortical synapses. Science 308:863-866.

Koester HJ, Sakmann B (2000) Calcium dynamics associated with action potentials in single nerve terminals of pyramidal cells in layer $2 / 3$ of the young rat neocortex. J Physiol 529:625-646.

Kolston J, Osen KK, Hackney CM, Ottersen OP, Storm-Mathisen J (1992) An atlas of glycine- and GABA-like immunoreactivity and colocalization in the cochlear nuclear complex of the guinea pig. Anat Embryol (Berl) 186:443-465.

Lüscher HR, Shiner JS (1990) Computation of action potential propagation and presynaptic bouton activation in terminal arborizations of different geometries. Biophys J 58:1377-1388.

Mackenzie PJ, Murphy TH (1998) High safety factor for action potential conduction along axons but not dendrites of cultured hippocampal and cortical neurons. J Neurophysiol 80:2089-2101.

Manis PB, Spirou GA, Wright DD, Paydar S, Ryugo DK (1994) Physiology and morphology of complex spiking neurons in the guinea pig dorsal cochlear nucleus. J Comp Neurol 348:261-276.

Markram H, Lübke J, Frotscher M, Roth A, Sakmann B (1997) Physiology 
and anatomy of synaptic connections between thick tufted pyramidal neurones in the developing rat neocortex. J Physiol 500:409-440.

Meeks JP, Jiang X, Mennerick S (2005) Action potential fidelity during normal and epileptiform activity in paired soma-axon recordings from rat hippocampus. J Physiol 566:425-441.

Molitor SC, Manis PB (2003) Dendritic Ca2 + transients evoked by action potentials in rat dorsal cochlear nucleus pyramidal and cartwheel neurons. J Neurophysiol 89:2225-2237.

Monsivais P, Clark BA, Roth A, Häusser M (2005) Determinants of action potential propagation in cerebellar Purkinje cell axons. J Neurosci 25:464-472.

Mugnaini E (1985) GABA neurons in the superficial layers of the rat dorsal cochlear nucleus: light and electron microscopic immunocytochemistry. J Comp Neurol 235:61-81.

Mugnaini E, Berrebi AS, Dahl AL, Morgan JI (1987) The polypeptide PEP-19 is a marker for Purkinje neurons in cerebellar cortex and cartwheel neurons in the dorsal cochlear nucleus. Arch Ital Biol 126:41-67.

Neu A, Foldy C, Soltesz I (2007) Postsynaptic origin of CB1-dependent tonic inhibition of GABA release at cholecystokinin-positive basket cell to pyramidal cell synapses in the CAl region of the rat hippocampus. J Physiol 578:233-247.

Niespodziany I, Poulain P (1995) Electrophysiology of the neurons in the area of the enkephalinergic magnocellular dorsal nucleus of the guineapig hypothalamus, studied by intracellular and whole-cell recordings. Eur J Neurosci 7:1134-1145.

Oertel D, Young ED (2004) What's a cerebellar circuit doing in the auditory system? Trends Neurosci 27:104-110.

Oertner TG, Sabatini BL, Nimchinsky EA, Svoboda K (2002) Facilitation at single synapses probed with optical quantal analysis. Nat Neurosci 5:657-664.

Oliva AA Jr, Jiang M, Lam T, Smith KL, Swann JW (2000) Novel hippocampal interneuronal subtypes identified using transgenic mice that express green fluorescent protein in GABAergic interneurons. J Neurosci 20:3354-3368.

Orduz D, Llano I (2007) Recurrent axon collaterals underlie facilitating synapses between cerebellar Purkinje cells. Proc Natl Acad Sci U S A 104:17831-17836.
Raastad M, Shepherd GM (2003) Single-axon action potentials in the rat hippocampal cortex. J Physiol 548:745-752.

Rubio ME, Juiz JM (2004) Differential distribution of synaptic endings containing glutamate, glycine, and GABA in the rat dorsal cochlear nucleus. J Comp Neurol 477:253-272.

Sawtell NB, Williams A, Bell CC (2007) Central control of dendritic spikes shapes the responses of Purkinje-like cells through spike timingdependent synaptic plasticity. J Neurosci 27:1552-1565.

Schmolesky MT, Weber JT, De Zeeuw CI, Hansel C (2002) The making of a complex spike: ionic composition and plasticity. Ann N Y Acad Sci 978:359-390.

Telgkamp P, Padgett DE, Ledoux VA, Woolley CS, Raman IM (2004) Maintenance of high-frequency transmission at Purkinje to cerebellar nuclear synapses by spillover from boutons with multiple release sites. Neuron 41:113-126.

Tzounopoulos T, Kim Y, Oertel D, Trussell LO (2004) Cell-specific, spike timing-dependent plasticities in the dorsal cochlear nucleus. Nat Neurosci 7:719-725.

Tzounopoulos T, Rubio ME, Keen JE, Trussell LO (2007) Coactivation of pre- and postsynaptic signaling mechanisms determines cell-specific spike-timing-dependent plasticity. Neuron 54:291-301.

Wadiche JI, Jahr CE (2001) Multivesicular release at climbing fiberPurkinje cell synapses. Neuron 32:301-313.

Williams SR, Stuart GJ (1999) Mechanisms and consequences of action potential burst firing in rat neocortical pyramidal neurons. J Physiol 521:467-482.

Wouterlood FG, Mugnaini E (1984) Cartwheel neurons of the dorsal cochlear nucleus: a Golgi-electron microscopic study in rat. J Comp Neurol 227:136-157.

Yasuda R, Nimchinsky EA, Scheuss V, Pologruto TA, Oertner TG, Sabatini BL, Svoboda K (2004) Imaging calcium concentration dynamics in small neuronal compartments. Sci STKE 2004:pl5.

Zhang S, Oertel D (1993) Cartwheel and superficial stellate cells of the dorsal cochlear nucleus of mice: intracellular recordings in slices. J Neurophysiol 69:1384-1397. 